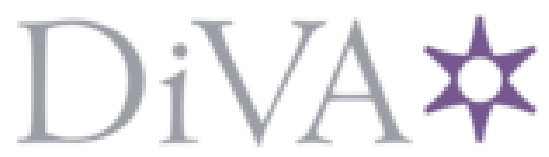

http://www.diva-portal.org

This is the published version of a paper presented at IECON 2014 - 40th Annual Conference of IEEE Industrial Electronics Society, October 29 - November 1, 2014, USA.

Citation for the original published paper:

Almas, M., Vanfretti, L. (2014)

Experimental Performance Assessment of a Generator's Excitation Control System using RealTime Hardware-in-the-Loop Simulation.

In: IEEE conference proceedings

N.B. When citing this work, cite the original published paper.

Permanent link to this version:

http://urn.kb.se/resolve?urn=urn:nbn:se:kth:diva-157126 


\section{Experimental Performance Assessment of a Generator's Excitation Control System using Real-Time Hardware-in-the- Loop Simulation}

\author{
M. S. Almas, L. Vanfretti \\ Electric Power Systems Departmeent \\ KTH Royal Institute of Technology \\ Stockholm, Sweden \\ \{msalmas, luigiv\}@kth.se
}

\author{
L. Vanfretti \\ R\&D Department \\ Statnett SF \\ Oslo, Norway \\ Luigi.vanfretti@statnett.no
}

\begin{abstract}
This paper presents methods and results for experimental performance assessment using Real-Time Hardware-in-the-Loop (RT-HIL) simulation of an Excitation Control System (ECS) for both terminal voltage regulation and power oscillation damping. The ECS configured for this study is Unitrol 1020 from $A B B$ and its performance is assessed for both Automatic Voltage Regulator (Auto) and Field Current Regulator (Manual) modes. RT-HIL simulation is performed by using Opal-RT's e MEGAsim RT Si mu lator using a power system model including a synchronous generator. Finally, the Power System Stabilizing feature of Unitrol $\mathbf{1 0 2 0}$ is calibrated and assessed.
\end{abstract}

Keywords-Excitation System, Synchronous Generator, Automatic Voltage Regulator, Field Current Regulator, Power System Stabilizer, Real-Time Simulation, Real-Time Hardware-inthe-Loop Simulation, Opal-RT, Unitrol 1020, SmarTS-Lab

\section{INTRODUCTION}

Synchronous generators are widely used in power systems as a source of electrical energy. They are equipped with sophis ticated control systems to adapt to frequent dynamical changes in the power system(e.g. load changes). One of such controls is the Excitation Control System (ECS) which provides direct current to the synchronous machine field winding and controls the terminal voltage [1]. In addition ECS als o provides protection functions to ensure that the capability limit of synchronous generators is never exceeded. Some of the important features of an ECS are synchronous generator's terminal voltage control, over and under excitation limiters, field current limiters and protections [2].

To guarantee the safe and reliable operation of a synchronous generator, the performance of ECS should be thoroughly verified under both steady and dynamic conditions. This can be achieved by using the Real-Time Hardware-in-the Loop (RT-HIL) [3] simulation approach. A performance as sessment of ABB's Unitrol 1020 Excitation Control System [4] for both voltage regulation and its capability for enhancing power system stability is carried out in this paper.

The paper is organized as follows: Section II provides information about the ABB's Excitation System Unitrol 1020 and test case modeling in MATLAB/Simulink. Section III presents the RT-HIL simulation for Automatic Voltage Regulation (Auto) and Field Current Regulation (Manual)

This work was supported in part by Nordic Energy Research through the STRONg2rid project and by Statnett SF, the Norwegian TSO.

M. S. Almas, and L. Vanfretti are with KTH Royal Institute of Technology, Stockholm, Sweden. (e-mail: \{msalmas, luigiv\}@kth.se)

L. Vanfretti, is with Statnett SF, Research and Development, Oslo, Norway (email: luigi.vanfretti@statnett.no) modes of controller using Opal-RT's eMEGAsim real-time simulator. Power system stabilizer configuration of the controller together with RT-HIL simulation results for interarea os cillation damping of the Klein-Rogers-Kundur power systemmodel are discussed in Section IV. Section V discusses the experimental results obtained and in Section VI, conclusions are drawn and future work is summarized.

\section{Unitrol 1020 Overview AND Test CASE Modeling}

\section{A. Unitrol 1020 Excitation Control System}

Unitrol 1020 is an automatic voltage regulator (AVR) that provides excitation control of indirectly excited synchronous machines and rotors [4]. The primary purpose of the device is to maintain the generator's terminal voltage while taking into accountall the operational limits as sociated to the generator [5]. The regulator can also bes witched over to function as field current regulator (Manual Mode), reactive power or power factor regulation. Figure 1 shows the single line diagram of a typicalgenerator which is receiving mechanical power input from a turbine and its field excitation is provided by an excitation control system. Terminal voltage of the generator is fed to the excitation system which compares this value to the set-point (reference voltage) and computes required field current to bring the terminal voltage to the reference value.

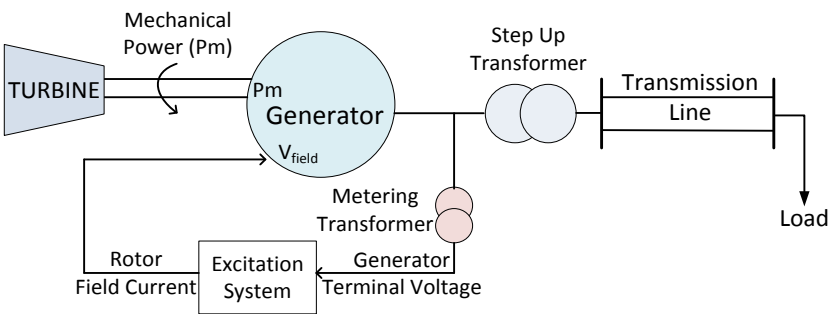

Fig. 1. Interaction between synchronous generator and excitation system

\section{B. Power System Test Case Modeling in MATLAB/Simulink}

Test case modeled in MATLAB/Simulink [6] for RT-HIL testing of Unitrol 1020 is shown in Figure 2. The generator modeled is a Turbo Generator (Round Rotor) of 50 MVA and nominal voltage of $20 \mathrm{kV}$. The parameters settings for the synchronous generator are presented in Table 1. Steam turbine and governor system provides mechanical power to the 
synchronous generator and regulates its frequency by increasing or decreasing the mechanical power input to the generator. The electrical power output of the generator is fed to the user-controlled dynamic load through step up transformer. The generator receives the field voltage fromUnitrol 1020. For this purpose one of the Analog Output of Unitrol 1020 is configured for Pulse Width Modulation (PWM) which is scaled between 0 and $100 \%$ to represent actual field voltage output of 0.5 to $99 \%$. Generator's terminal voltage (single phase), stator current (single phase) and field current are fed to Unitrol 1020 by using Analog Outputs of Opal-RT's eMEGAsim Real-Time Simulator [7].

\section{Interfacing Unitro 1020 with Opal-RT's eMEGAsim Real- Time Simulator}

Real-Time Simulator (RTS) can only provide voltages upto $\pm 10 \mathrm{~V}$ and currents upto $\pm 20 \mathrm{~mA}$. These low-level signals (generator terminal voltage and stator current) are amplified using linear amplifiers to scale voltage upto $100 \mathrm{~V}$ and currents to 1 Ampere at rated power [8]. The field current measurement is supplied to Unitrol 1020 using low-level \pm 10 Volts. For this purpose one of the inputs of Unitrol 1020 is configured for receiving an external excitation current. The complete connection diagram is shown in Figure 3.

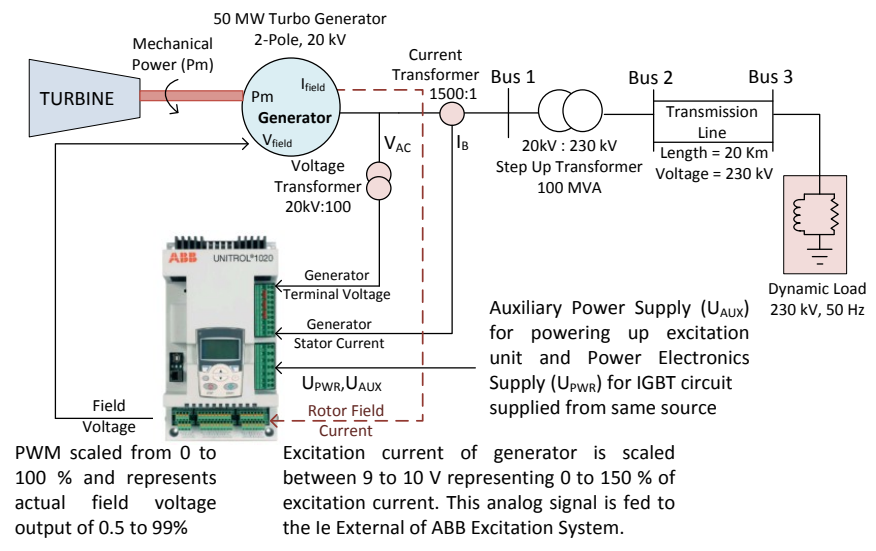

Fig. 2. Single line diagram of test case model developed in MATLAB/Simulink for RT-HIL execution of Unitrol 1020.

TABLE I

Generator Parameter Settings

\begin{tabular}{|l|l|}
\hline \multicolumn{1}{|c|}{ Parameter } & \multicolumn{1}{c|}{ Value } \\
\hline Nominal Power & $50 \mathrm{MVA}$ \\
\hline Line-to-Line Voltage & $20 \mathrm{kV}$ \\
\hline Frequency & $50 \mathrm{~Hz}$ \\
\hline Reactances (Xd, Xd', Xd', Xq, Xq', Xq', & $2.20,0.2,0.20,2.00,0.4$, \\
Xl) & $0.20,0.15(\mathrm{pu})$ \\
\hline Time constants (Tdo', Tdo', Tqo', Tqo') & $4.0,0.05,1.5,0.05(\mathrm{~s})$ \\
\hline Inertia Cofficient H (s) & 3 \\
\hline Pole Pairs & 1 \\
\hline
\end{tabular}

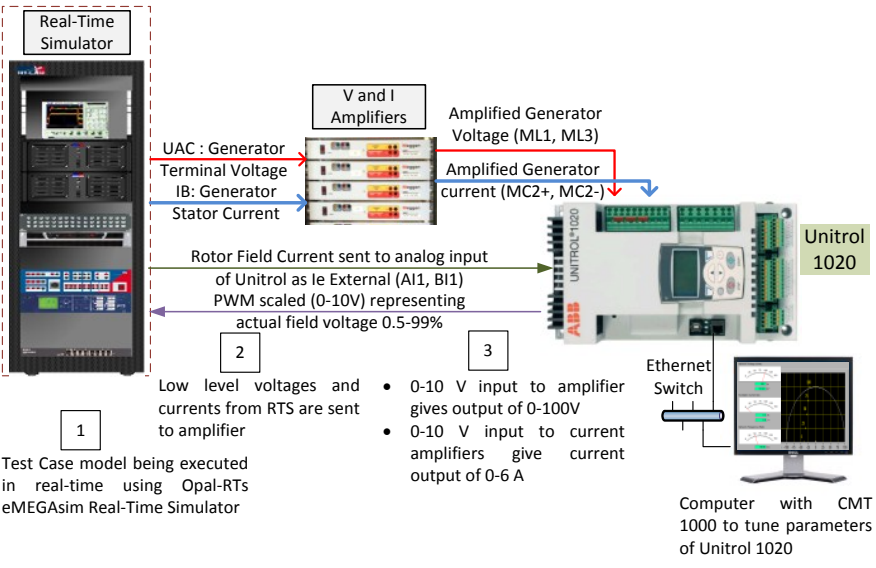

Fig. 3. Connection Diagram for interfacing Opal-RT with Unitrol 1020

Configuration settings for Unitrol 1020 are shown in Figure 4 together with screenshots showing configuration of the analog I/Os for this study. The parameter setting for "Ie No Load" is measured by executing the test case model under noload. The model initially executes with a fixed field voltage (configured inside the simulation model) to achieve steady state and then the user can send a command in real-time to switch to the field voltage measurements supplied by ABB Excitation system.

III. RT-HIL AsSEssment of Volt age Regulation (Auto) and Field Current Regulation (Manual) Modes

\section{A. Automatic Voltage Regulation (Auto) Mode}

In AUTO mode, Unitrol acts as an AVR with all its operational limiters active as shown in Figure 5. The model was initially executed at no-load and with a fixed excitation voltage configured in the model. Once the steady state is reached, Unitrol 1020 takes over the exciter in the RTS model. A Series ofdisturbances were introduced by increasing both the active and reactive power consumption of the load. The different experiments performed to assess the performance of the Auto mode are presented in Table 2.

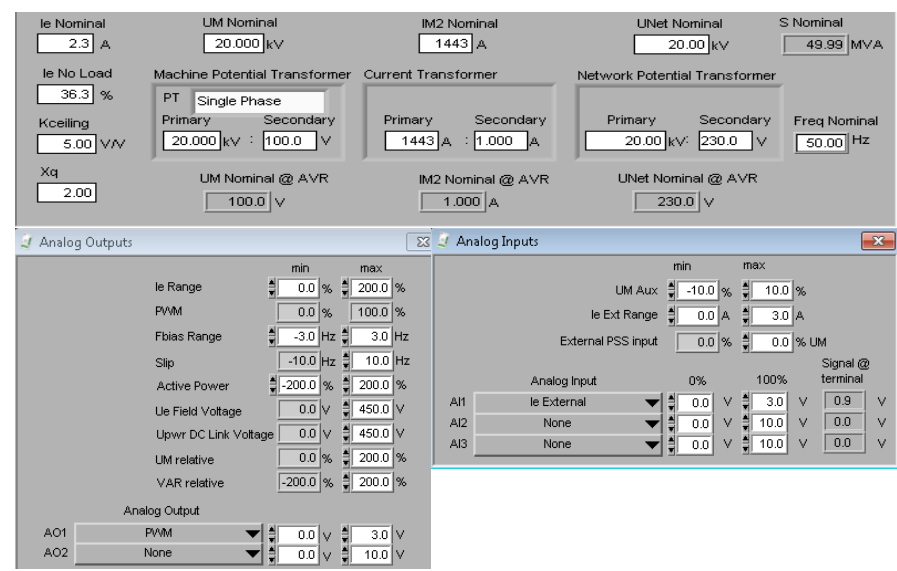

Fig. 4. Unitrol System Data and Analog I/Os configuration for RT-HIL simulation. 


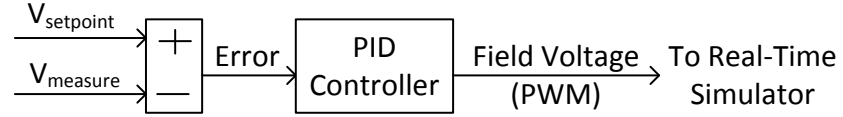

Figure 5: Auto Mode of Unitrol 1020

TABLE 2

DisTURBANCES INCORPORATED IN THE TEST CASE SYSTEM (Automatic Voltage Regulation Mode)

\begin{tabular}{|l|l|l|l|}
\hline Event & $\begin{array}{l}\text { Instance } \\
\text { (sec) }\end{array}$ & Disturbance & $\begin{array}{l}\text { Change in } \\
\text { Load }\end{array}$ \\
\hline 1 & $\mathrm{t}=0$ & Simulation starts (no load) & 0 \\
\hline 2 & $\mathrm{t}=47.1$ & ABB Excitation System takes over & 0 \\
\hline 3 & $\mathrm{t}=108.9$ & Load increase 10 MW and 10 MVAR & $\begin{array}{l}+10 \mathrm{MW}, \\
+10 \mathrm{MVAR}\end{array}$ \\
\hline 4 & $\mathrm{t}=171.3$ & Load increase to 20MW \& 10 MVAR & $+10 \mathrm{MW}$ \\
\hline 5 & $\mathrm{t}=222.0$ & Load increase to 30 MW \& 10 MVAR & $+10 \mathrm{MW}$ \\
\hline 6 & $\mathrm{t}=272.4$ & Load increase to 35 MW \& 10 MVAR & $+5 \mathrm{MW}$ \\
\hline 7 & $\mathrm{t}=319.5$ & Load increase to 35 MW \& 15 MVAR & $+5 \mathrm{MVAR}$ \\
\hline 8 & $\mathrm{t}=407.1$ & Load increase to 37 MW \& 15 MVAR & $+2 \mathrm{MW}$ \\
\hline 9 & $\mathrm{t}=482.1$ & Load cut off (no load condition) & $\begin{array}{l}-37 \mathrm{MW}, \\
-15 \mathrm{MVAR}\end{array}$ \\
\hline
\end{tabular}
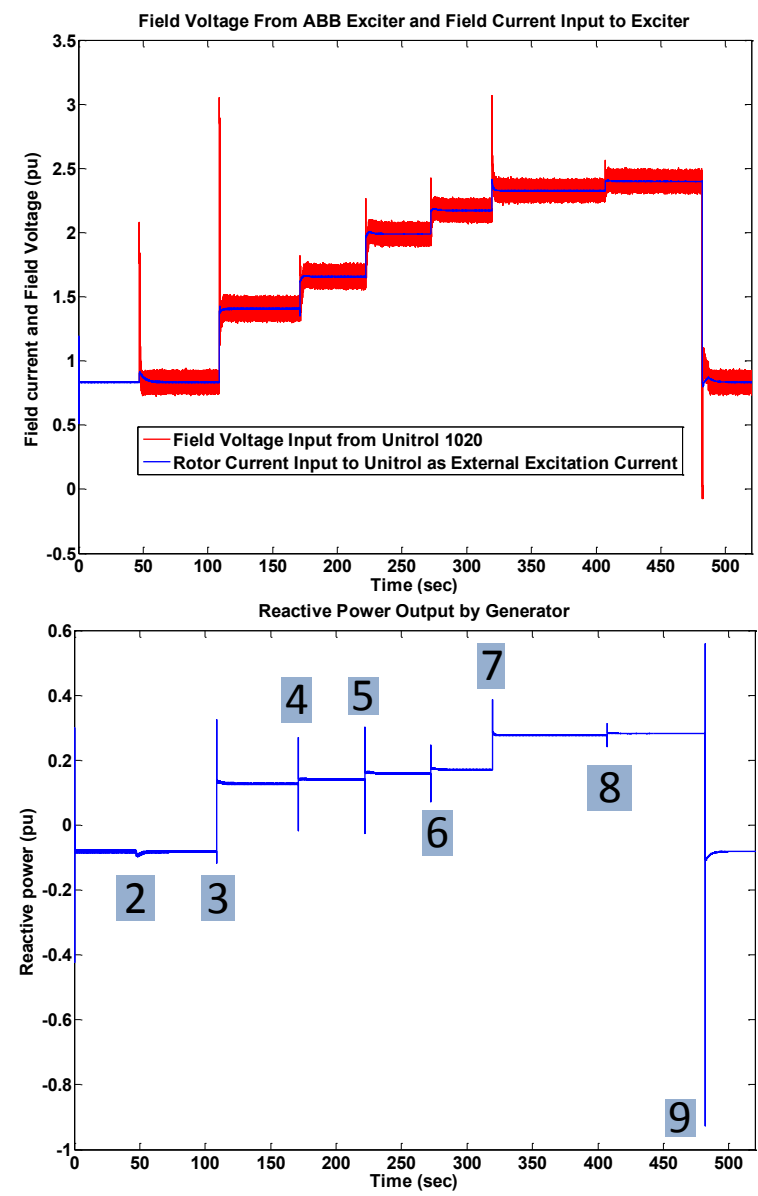
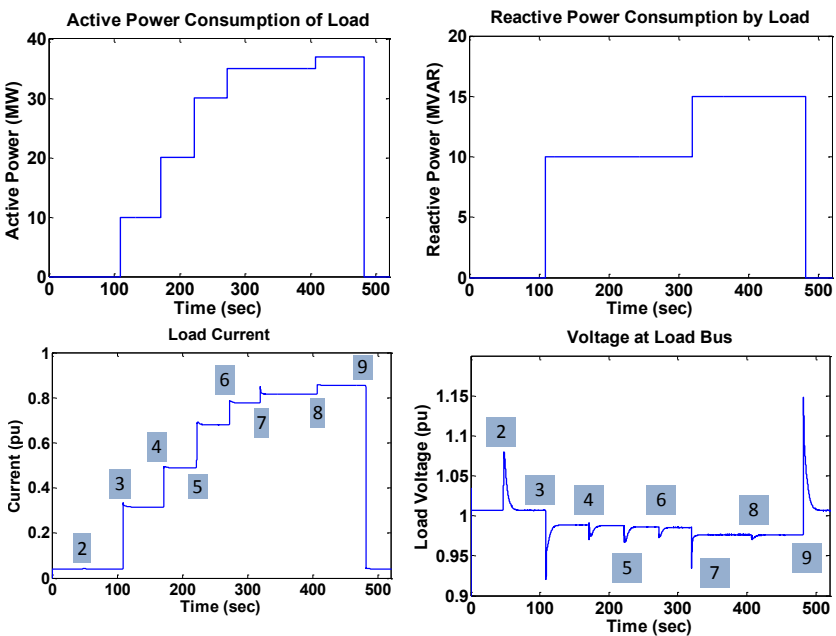

Fig. 6. Load characteristics when subjected to disturbances as listed in Table 2. The number corresponds to the events as per Table-2. The voltage at load bus decreases with an increase in load.
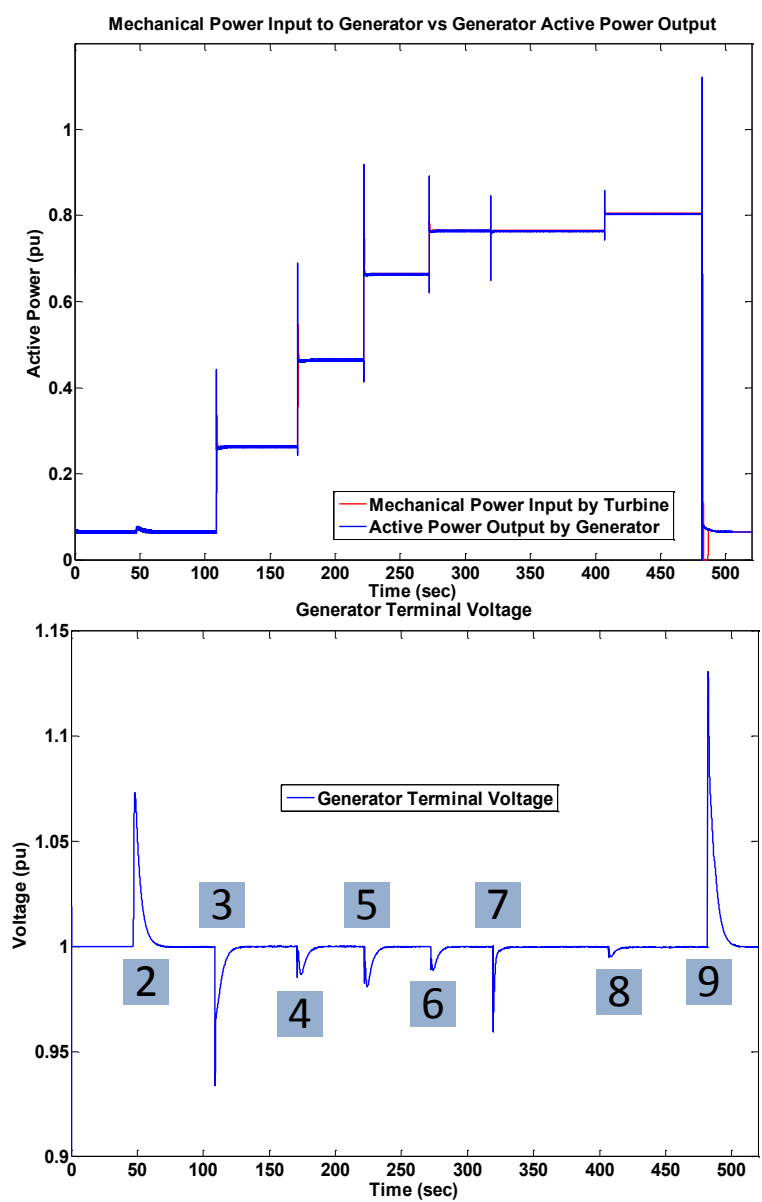

Fig. 7. Generator characteristics when subjected to disturbances listed in Table 2. The Excitation is provi ded by Unitrol 1020 in Automatic Voltage Regulation (Auto) Mode. Note that the generator terminal voltage (bottom right plot) is at 1 pu. The field voltage input provided by Unitrol 1020 (top left plot) increases with the change in the load to keep terminal voltage of generator strictly to $1 \mathrm{pu}$. The highest positive peak in generator terminal voltage (bottom-right) correspond to Event 9 when the complete load is cut-off(37MW, 15MVAR) and causes a momentarily increase in the terminal voltage. This is detected by Unitrol 1020 and it regulates the field voltage to bring terminal voltage to the reference $(1 \mathrm{pu})$. The positive peak can be reduced by narrowing the operational limits of terminal voltage in Unitrol 1020 . For this study the voltage regulation range is $80-120 \%$ of nominal terminal voltage. 


\section{B. Field Current Regulation (Manual) Mode}

In manual mode Unitrol 1020 acts as field current regulator as shown in Figure 8. The limiters are not active in this mode and the generators terminal voltage is no more maintained. Figure 9 shows the important parameter settings for manual mode operation of Unitrol 1020. The same model used for evaluating Auto Mode is used here.

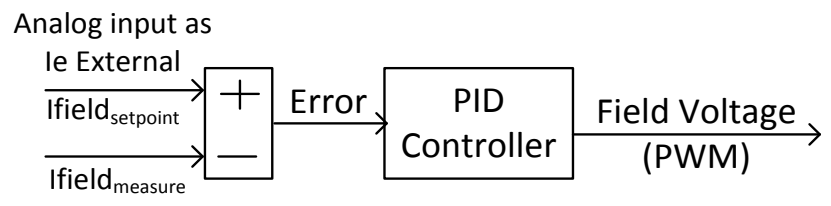

Figure 8: Manual Mode of Unitrol 1020

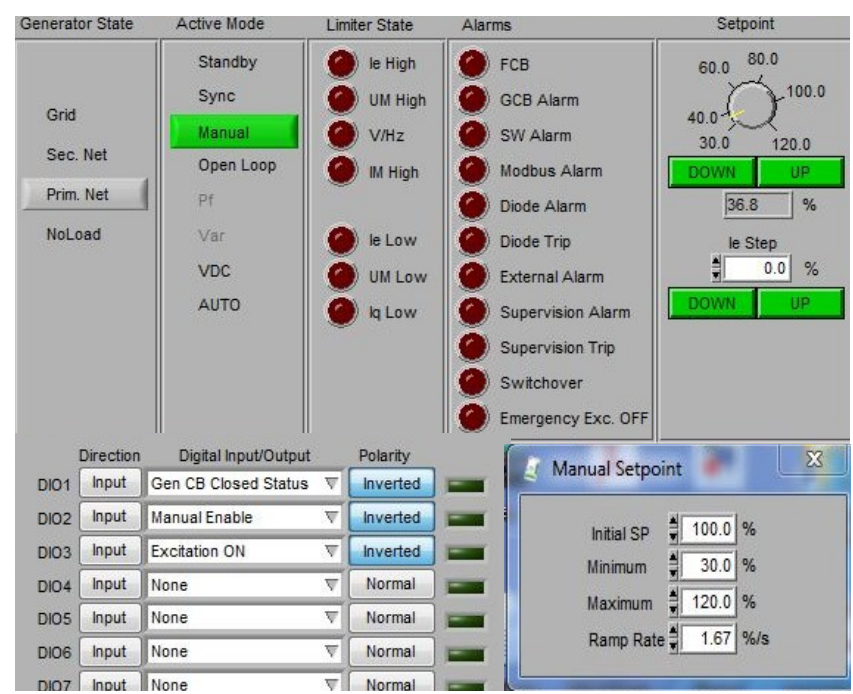

Figure 9: Parameter settings for manual mode operation of Unitrol 1020
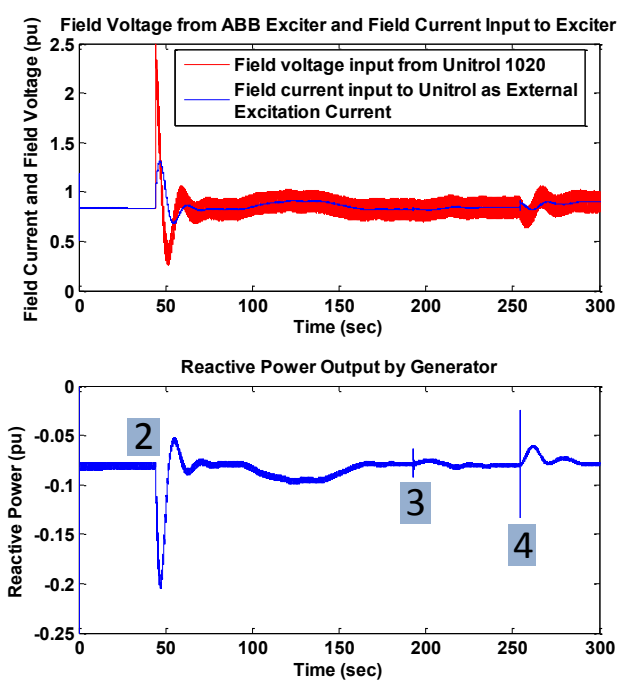

The model was initially executed at no-load and with a fixed excitation voltage configured in the model. Once the steady state is reached, Unitrol 1020 takes over the exciter in the RTS model. A series of disturbances were made by increasing the active power consumption of the load. The variation in generator's terminal voltage was compensated by manually increasing the field current setpoint of Unitrol 1020. Only small disturbances were applied for testing the manual mode in order to maintain the generator's synchronism and avoiding the real-time simulation from crashing. The experiments carried out are presented in Table 3.

TABLE 3

DisTURBANCES INCORPORATED IN THE TEST CASE SySTEM (FIELd CURRENT REgulation Mode)

\begin{tabular}{|l|l|l|l|}
\hline Event & $\begin{array}{l}\text { Instance } \\
\text { (sec) }\end{array}$ & Disturbance & $\begin{array}{l}\text { Change in } \\
\text { Load }\end{array}$ \\
\hline 1 & $\mathrm{t}=0$ & Simulation starts (no load) & 0 \\
\hline 2 & $\mathrm{t}=44$ & $\begin{array}{l}\text { ABB Excitation System } \\
\text { takes over }\end{array}$ & 0 \\
\hline 3 & $\mathrm{t}=193$ & Load increase 1 MW & $+1 \mathrm{MW}$ \\
\hline 4 & $\mathrm{t}=254.4$ & Load increase to 5MW & $+4 \mathrm{MW}$ \\
\hline
\end{tabular}
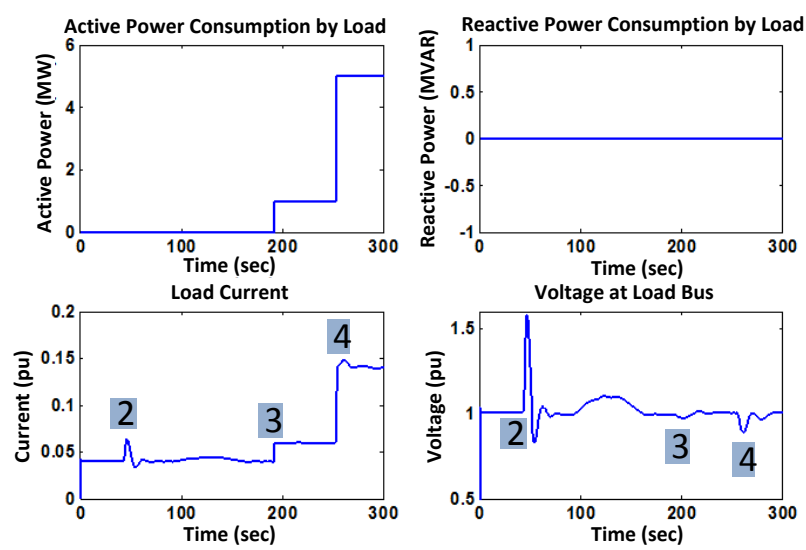

Fig. 10. Load characteristics when subjected to disturbances listed in Table 3. Note the change in bus voltage (bottom right plot) with the increase in load.
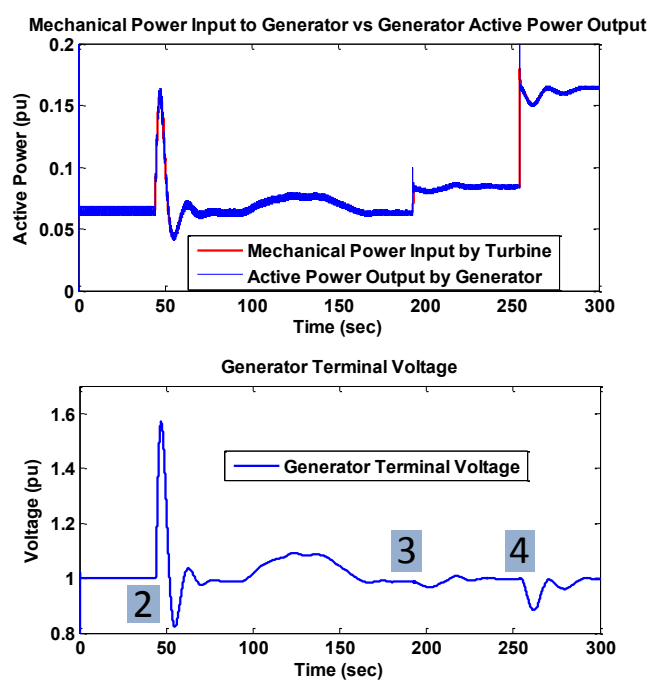

Fig. 11. Generator characteristics when subjected to disturbances listed in Table 3. The Excitation is provided by Unitrol 1020 in Field Current Regulation (Manual) Mode. Note that the generator terminal voltage (bottom right plot) is no more kept constant to 1 pu. The field voltage output by Unitrol 1020 is manually increased by changing manual set-point of the field current shown in Figure 9. 
IV. Power System Stabilizer (PSS) Calibration and ASSESSMENT

Small disturbances such as changes in loads or large disturbances like generator outage or a high voltage transmission line fault may result in undamped power oscillations in a heavily loaded interconnected power system [9]. Undamped oscillations if not adequately addressed, result in loss of synchronismof one or group of machines from the rest of the power system and may cause the system to collapse. This is called rotor angle instability and is mostly dominated by low frequency inter-area oscillations [10].

In order to provide adequate damping to these inter-area oscillations, Power System Stabilizers (PSS) [11] and supplementary control of Flexible AC Transmission Systems (FACTS) devices are utilized and are referred as Power Oscillation Dampers (POD) [12].

\section{A. Power System Stabilizer (PSS)}

The PSS is a feedback controller and is part of the control systemofa synchronous generator, which acts through the excitation system to providean additional signal to modulate the field voltage. The main function of PSS is to damp generator rotor oscillations in the range from 0.1 to $2.5 \mathrm{~Hz}$, which are called electromechanical oscillations.

The simplest method to provide a damping torque in the synchronous machine is to measure the rotor speed and use it directly as an input signal in the stabilizer structure. The simplest one is known as IEEE PSS1A model [13] and is documented in the IEEE Standard 421.5-2005 [5]. It is illustrated in Figure 12. It consists of a low-pass filter, a general gain, a washout filter which is effectively a high-pass filter, a phase-compensation system in the form of lead-lag compensator, and an output limiter. The general gain " $\mathrm{K}$ " is proportional to the amount of damping produced by the stabilizer. The washout high-pass filter allows the PSS to respond only to transient variations in the speed input signal " $\mathrm{d} \boldsymbol{\omega}$ ". The phase-compensation systemis represented by leadlag transfer functions used to compensate the phase lag between the excitation voltage and the electrical torque of the synchronous machine. The output limiter ensures to bound the amount of control action of a PSS during a major system disturbance and thus avoids the PSS to adversely affect the generator's synchronism.

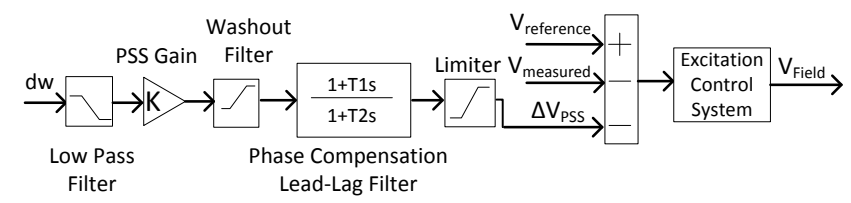

Fig. 12. Model of a conventional $\Delta \omega$ PSS [12].

\section{B. PSS Feature of Unitrol 1020 Excitation System}

PSS feature available in Unitrol 1020 ECS is represented by the IEEE Std. 421.5-2005 PSS 2A/2B model [5] and its simplified representation is shown in Figure 13. The PSS2A type has dual structures that use two signals of angular velocity " $\omega$ " and power "P" as compared to single input of angular velocity $\omega$ in PSS1A model shown in Figure 12.

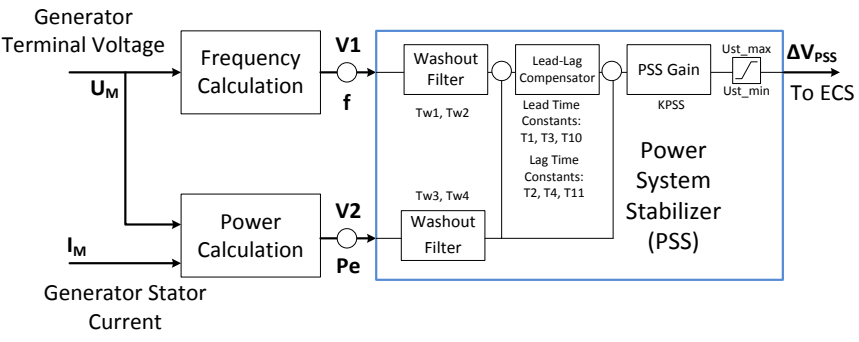

Fig. 13. Simplified model of PSS incorporated in Unitrol 1020 ECS. The calculated frequency and electric power Pe is fed to the PSS as voltage signals

\section{Power System Modeling and Calibration of PSS Parameters}

In order to investigate the performance of Unitrol 1020 for power system stabilization (PSS), the Klein-Rogers-Kundur test system [14] was modeled in the MATLAB/Simulink environment using the SimPowerSystems toolbox. The single line diagram of the test case is shown in Figure 14. The test sys tem consists of two fully symmetrical areas linked together by two $230 \mathrm{kV}$ lines of $220 \mathrm{~km}$ length. Each area is equipped with two identical round rotor generators rated $20 \mathrm{kV} / 900$ MVA. The nominal power system frequency for the test case model is $50 \mathrm{~Hz}$. It was specifically designed to study low frequency electromechanical oscillations in large interconnected power systems. The load is represented as constant impedances and split between the areas in such a way that area 1 is exporting power to area 2.

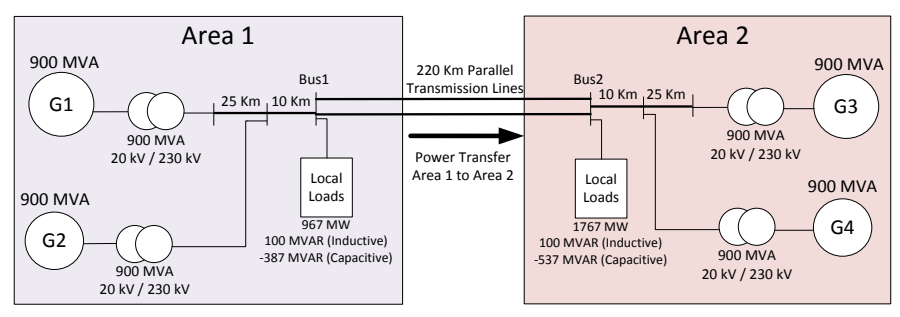

Fig. 14. Single line diagram of the test case power system

In order to analyze the response of the power system, a large disturbance in the formof three phase to ground fault (8 cycles i.e. $160 \mathrm{msec}$ ) at $\mathrm{t}=20 \mathrm{sec}$ is introduced in the middle of one of the two $220 \mathrm{~km}$ transmission line connecting Area 1 with Area 2. The system response to this perturbation in absence of PSS is shown in Figure 15. This results in an undamped os cillation of $0.64 \mathrm{~Hz}$ which is observable in the tieline power transfer between Area 1 and Area 2 as shown in Figure 13. This is an inter-area mode involving both the machines in Area 1 oscillate against the machines in Area 2. The PSS capability of Unitrol 1020 is exploited to damp this inter-area mode of $0.64 \mathrm{~Hz}$.

The PSS parameter settings are configured according to the recommendations in the IEEE Standard 421.5-2005 [5] and are presented in Table-4. The gain of PSS is deliberately kept low along with low positive and negative limits of PSS output to avoid major changes in the field voltage due to large disturbances which could lead to generator's loss of synchronism and to minimize the influence of noise. 

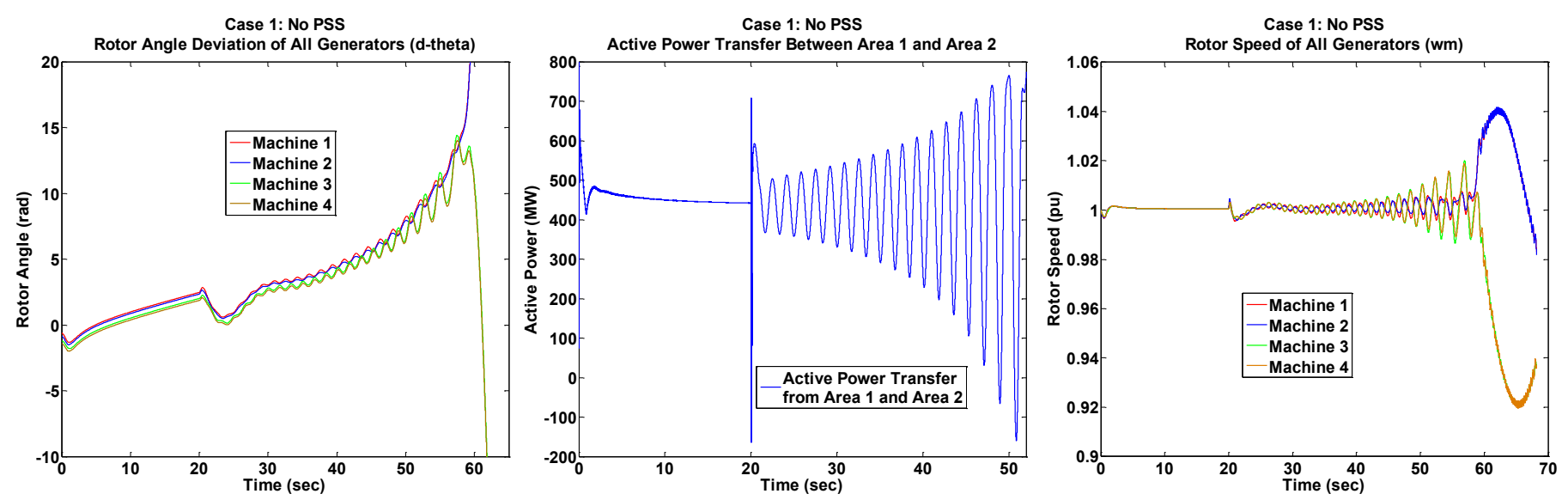

Fig. 15. Response of Test Model when three phase to ground fault ( 8 cycles $)$ is introduced at the middle of one of the $220 \mathrm{kV}$ transmission lines at $\mathrm{t}=20 \mathrm{sec}$. Rotor angle deviation of machines with reference to rotor angle deviation of Machine 4 (left), power transfer from Area 1 to Area 2 (middle) and rotor speed of all the generators (right) are shown. Inter-area oscillation of $0.64 \mathrm{~Hz}$ is observable in the tie-line power (middle). The PSS capability of Unitrol 1020 is disabled in this case.
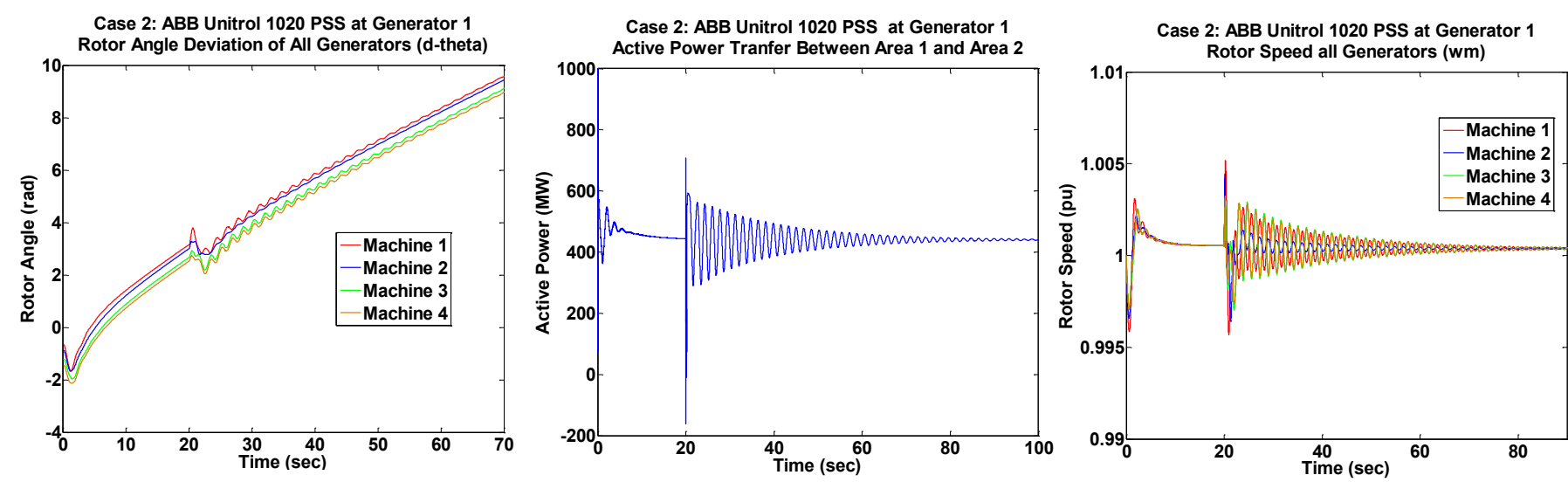

Fig. 16. Response of Test Case model when three phase to ground fault ( 8 cycles) is introduced at the middle of one of the $220 \mathrm{kV}$ tran smission lines at $\mathrm{t}=20 \mathrm{sec}$ when Generator 1 is equipped with PSS and AVR through Unitrol 1020 ECS. Inter-area oscillation of $0.64 \mathrm{~Hz}$ is adequately damped. The response of PSS can be enhanced by fine tuning of PSS lead-lag compensation parameters and by increasing the PSS gain.

Figure 16 shows the response of the PSS integrated within Unitrol 1020 ECS coupled to Generator 1 when subjected to large disturbance. All the generators remain in 'synchronism after the disturbance and the system soon achieves nominal operating conditions. Figure 17 shows the plot of field voltage supplied by Unitrol ECS to Generator 1 .

TABLE 4

IMPORTANT PARAMETER SETTINGS OF PSS IN UNITROL 1020

\begin{tabular}{|l|l|l|}
\hline Parameter & Description & Setting \\
\hline Tw1, Tw2 & $\begin{array}{l}\text { Washout time constants for } \\
\text { frequency channel }\end{array}$ & $5.0 \mathrm{~s}, 5.0 \mathrm{~s}$ \\
\hline Tw3, Tw4 & $\begin{array}{l}\text { Washout time constants for } \\
\text { power channel }\end{array}$ & $5.0 \mathrm{~s}, 0 \mathrm{~s}$ \\
\hline T1, T3, & Lead time constants & $0.03 \mathrm{~s}, 0.03 \mathrm{~s}$, \\
T10 & Lag time constants & $1 \mathrm{~s}, 1 \mathrm{~s}, 0 \mathrm{~s}$ \\
\hline T2, T4, & T11 & $0.1 \mathrm{pu},-0.1 \mathrm{pu}$ \\
\hline Ust_max, & $\begin{array}{l}\text { Maximum and minimum limit } \\
\text { value of PSS signal }\end{array}$ & \\
\hline
\end{tabular}

Case 2: ABB Unitrol 1020 PSS at Generator 1

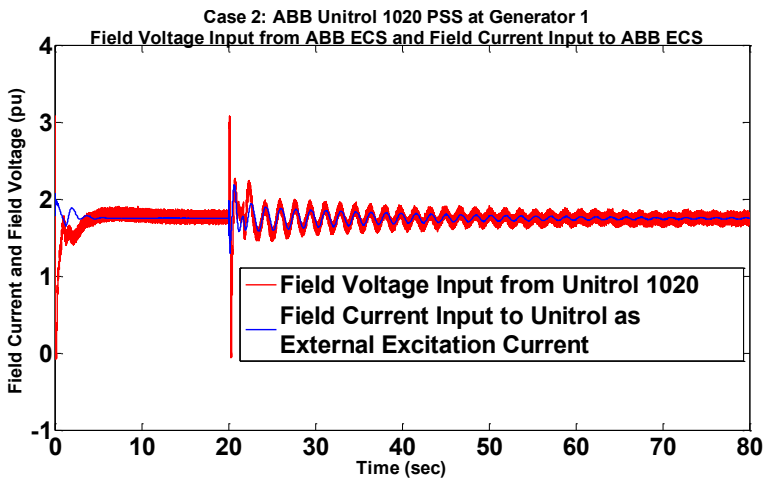

Fig. 17. Field Voltage supplied by Unitrol 1020 to Generator 1 when subjected to large disturbance with PSS feature enabled.

\section{Discussion of RT-HIL SimUlation Results}

In Automatic Voltage Regulation (Auto) mode, Unitrol 1020 successfully maintains the voltage at generator's terminal when subjected to step increase in load demand as shown in Figure 7. Some overshoots are observed in field voltage input fromUnitrol 1020 to generator's model being 
executed in real-time simulator especially when load's reactive power demand is increased. These overshoots can be reduced by proper tuning of the PID controller parameters. For the overall test run, the voltage remained maintained at $1 \mathrm{pu}$ at generator's terminal.

Manual Mode is much difficult to test using the RTS when subjected to load increase as the decrease in terminal voltage due to load increase is much faster than the human response to increase the setpoint of field voltage manually. This is the reason for adding only small load variations while performing RT-HIL simulation for Unitrol 1020 in manual mode.

The field voltage analog input signal from Unitrol 1020 has some noise in it (e.g. Figure 11) where red line does have its mean at around 0.85 but the signal has noise. This can be countered in the simulation by adding a discrete mean block which computes the average of this analog input and then feeds it to the input of the generator model. However this has not caused any issues during RT-HIL. There is always a small variation between the active /reactive power shown by CMT 1000 (Unitrol 1020 configuration software) [15] as compared to the measurements seen with the simulation interface. The reason is dueto series of scaling of the signals performed to remain within the threshold limits of Opal-RT's analog outputs and the amplifiers inputs. The whole scaling procedure adopted for this study is shown in Figure 16. The small variations are likely due to the low dynamic range of the $\mathrm{D} / \mathrm{A}$ converters of the simulator.

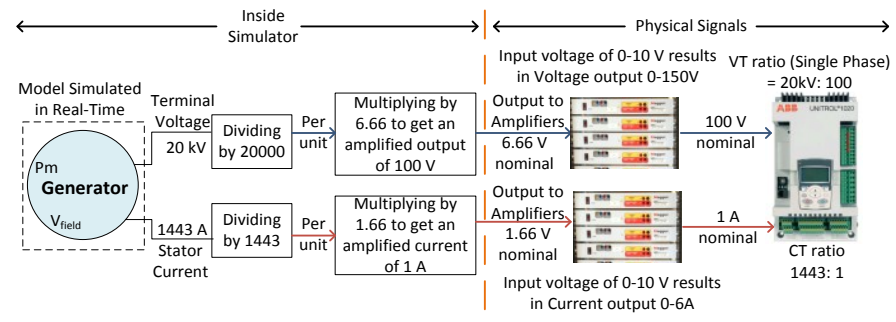

Figure 16: Signal scaling stages in the experimental setup.

\section{CONClusion AND Future Work}

Real-time hardware-in-the-loop simulation of an excitation control system(Unitrol 1020) is performed using Opal-RT's eMEGAsim real-time simulator. The performance of the ECS is analyzed for both Automatic Voltage Regulation (Auto) Mode and Field Current Regulation (Manual Mode) for a $50 \mathrm{MVA}$ generator together with subsequent power system executed in realtime. The power system stabilization capability of the ECS is evaluated by utilizing the ECS to provide adequate damping for an inter-area oscillation in a test case power system model by using the RT-HIL simulation approach. The RT-HIL results have shown that Unitrol 1020 effectively maintains generator's terminal voltage to $1 \mathrm{pu}$ in A VR (Auto) Mode. The PSS feature of Unitrol 1020, when enabled, provides adequate damping to inter-area oscillations.
Unitrol 1020 has the capability to receive external PSS signals. This capability of Unitrol 1020 is currently being explored to provide remote signals based on synchrophas or measurements to the ECS to provide optimum damping to the oscillatory modes. In addition the System-in-the-Loop (SITL) package [16] together with OPNET network simulator is being configured in the SmarTS-Lab to simulate network delays and latencies in the feedback signal for damping controls to effectively address the effect of communication delays in power system stability. These results will be submitted in a future publication.

\section{ACKNOWLEDGMENT}

KTH SmarTS-Lab would like to thank ABB Switzerland AG for their donation of Unitrol 1020 Excitation System.

\section{REFERENCES}

[1] F.P. deMello and C. Concordia "Concepts of synchronous machine stability as affected by excitation control", IEEE Trans. on Power, Apparatus and Systems, vol. 88, no. 4, pp.316 -329, 1969

[2] IEEE Guide for "Synchronous Generator Modelling Practices in Stability Analyses,", Power System Engineering and Electric Machinery Committees of the IEEE Power Engineering Society, IEEE Std.1110-1991

[3] W. Grega, "Hardware-in-the-loop simulation and its application in control education", 29th ASEE/IEEE Frontiers in Education Conference, Session 12b6, pp, 7-12, November, 1999.

[4] ABB-Unitrol 1020 Automatic Voltage Regulator, available online: http://tinyurl.com/Unitrol

[5] IEEE Standard 421.5-2005, "IEEE Recommended Practice for Excitation System Models for Power System Stability Studies", 2006, DOI: 10.1109/IEEESTD.2006.99499

[6] "SimPowerSystems User's Guide" by "The MathWorks" available at http://www.mathworks.com/help

[7] Opal-RT, "eMEGAsim PowerGrid Real-Time Digital Hardware in the Loop Simulator", Available online: http://www.opal-rt.com/.

[8] "Current and Voltage Amplifiers by Megger," available on-line: http://www.megger.com/cae/story/Index.php? ID=527.

[9] F.P. deMello and T.F. Laskowski "Concepts of power system dynamic stability", IEEE Trans. on Power, Apparatus and Systems, vol. 94, pp.827 -833,1979

[10] M. Klein , G. Rogers and P. Kundur "A fundamental study of interarea oscillations in power systems", IEEE Trans. Power Syst., vol. 6, no. 3, pp.914 -921 1991

[11] D.C. Lee , R.E. Beaulieu and J.R.R. Service "A power system stabilizer using speed and electrical power input - design and field experience", IEEE Trans. on Power, Apparatus and Systems, vol. 100, no. 4, pp.276 -284, 1981

[12] L. Angquist, B. Lundin and J. Samuelsson, "Power oscillation damping using controlled reactive power compensation-a comparison between series and shunt approaches", IEEE Transactions on Power Systems, Vol. 8 , No. 2, July 1993 , pp. $687-700$

[13] M. Klein, J. Rogers, S. Moorty and P. Kundur: "Analytical investigation of factors influencing PSS performance," IEEE Transactions on Energy Conversion, Vol. 7 , No 3, September 1992, pp. 382-390

[14] P. Kundur; M. Klein G. J. Rogers and M. S. Zywno, "Application of Power System Stabilizers forEnhancement of Overal 1 System Stability", IEEE Transactions on Power Systems, Vol. 4, No. 2, August 1989, pp. 614-626

[15] ABB, "Commissioning and Maintenance Tool CMT 1000 for Unitrol 1020 ECS", Available online: http://tinyurl.com/Unitrol

[16] K. McNeill, R. Martinez, W. Wu, and J. Deal, "HITL /SITL General Reference Model," OPNETworks 2003 Symposium, Washington DC, August 2003 